\title{
Function Construction of Think Tanks in the Teaching Management Platform of Universities
}

\author{
Jiang $\mathbf{L i}^{*}$ \\ College of Marxism, Nanjing University of Technology, Nanjing 210094, Jiangsu Province, China \\ *Corresponding author: Jiang Li, $2797438021 @$ qq.com
}

\begin{abstract}
In the new era of knowledge and information, knowledge, as the support of management and power development, increasingly reflects its own value. As the advanced platform for knowledge dissemination, research, and cultivation of knowledge talents, colleges and universities need to cultivate compound and multi-functional talents. This is becoming more and more important in the reality of social, economic, and cultural development. They also need to be protected and supported by rules, decisions, and systems that are relatively wise, rational, and conform to the development laws of education and teaching. Educational administration institutions in colleges and universities should not only assume traditional responsibilities such as teaching management and resource allocation, but also establish their own rational decision-making mechanism and framework driven by development trends to form similar think tank functions or think tank attributes as well as gradually promote the construction of such management system in various teaching institutions, organizations, and departments to ensure that the teaching platform can become a new management and decision-making center.
\end{abstract}

Keywords: Think tank; Management system; System construction

Publication date: November 2021; Online publication: November 30, 2021

\section{Introduction}

The advent of the new knowledge era makes colleges and universities, as the source of talent cultivation, management, and transportation, play an increasingly important role in the process of social operation, development, and progress. Combined with the previous teaching management mode and style, talents in the new knowledge and technology era have strong creativity, wide knowledge range, and practical skills, which need to be improved. They need to ensure the full management of their creativity and thinking skills in different fields. They also need to reduce the pressure and compulsion in the traditional management style, improve the guiding power, and strengthen students' thinking. This means that the administrative style and management system of many colleges and universities are gradually operating a relatively rigid trend. It is urgent for the teaching staffs, scientific researchers, and management decision-makers in colleges and universities to change the roles of teachers and students, reform the management mode, and promote the transition from management to service. Its essence lies in transforming the teaching management platform of colleges and universities to a multi-functional think tank or rational decisionmaking platform as well as realizing the reset and reform of the management mode in the process, so as to adapt to the current rapidly changing economic and cultural development trend, promote communication between teachers and students, strengthen the exchange of academic ideas, break down departmental barriers, allow the all-round flow of teaching resources, and enhance the rationality of the teaching management and reform. 


\section{The urgent need for transformation in the management center attribute of teaching and scientific research management platforms in universities}

The new era of knowledge economy has the characteristics of multi-fields, pluralism, and comprehensiveness, which are not available in the industrial era for the development of high and new technology, industrial integration, multi-field development, and intelligent management. The talents required by the development trend in various fields need to possess multiple skills, such as teaching management, theoretical research in higher education, technological research and development, as well as strategic decision-making. This will greatly change the traditional teaching curriculum, training plan, teaching style, and the research relationship between teachers and students. In general, the establishment of teaching and scientific research management platforms in colleges and universities is mainly based on students' education and the pressure to complete teachers' tasks, understand and apply knowledge, as well as lay the foundation of disciplines and skills. Teaching and scientific research management platforms only need to undertake the roles of collection, mobilization, guarantee, and distribution of teaching resources ${ }^{[1]}$. However, in the era of diversified development, the single function of teaching and scientific research platforms for high-end talents and scientific research groups with comprehensive ability in colleges and universities is no longer suitable for the current trend of joint development of social industries. According to surveys and teaching management practices in several science and engineering or humanities and social sciences universities, due to professional bias, educational administration institutions, scientific research platforms, and teacher development centers are required to undertake training as well as organize forums and teaching courses. It is necessary to assume the role of a decision-making body, and then gradually resemble the function of a think tank, so as to transmit "thinking," revise "ideas," and shift from an administrative body to a service body. At present, many teaching institutions and teaching development centers have not completed this kind of transformation, so they cannot be identified as real think tanks for the time being.

\section{The necessity of changing the teaching management platform of universities to the function development trend of multi-function think tanks}

As for the phenomenon that most colleges and universities have started to set up teaching management think tanks but lacking in construction and management experience, it is difficult for the teaching management platform of colleges and universities to balance the original functions of teaching resources, curriculum arrangement, venue organization, etc. in a short period of time, while the limitations of the discipline and the specialty of the managers themselves precipitate an inefficient operation of the management system, resulting in a rigid state. Through the management platform, a prototype similar to a think tank will be constructed step-by-step, forming a think tank structure, and then having certain functions to lay a foundation for future transformation into a think tank.

The teaching management platform in colleges and universities has become a gathering place for the development of new compound talents and new thinking. Rational decision-making and diversified management modes are needed to adapt to the characteristics of talent development in the new era. The greatest feature of knowledge economy and network era is that it is constructed through the full integration of high and new technologies, platforms, and knowledge networks of institutions of higher learning. It permeates all walks of life and attracts elite talents from population settlements, such as major cities, to settlement areas with institutions of higher learning, as well as scientific research institutions as the core. The perspective and mode of thinking that it forms would be a long-distance multi-dimensional management thinking, which is maintained by comprehensive ability, cross-industry, and cross-distance. Its most obvious characteristics are compound, three-dimensional perspective, and development concept. It combines the comprehensive and multi-dimensional mode of thinking with management channels and 
provides professional services such as multi-decision making and suggestions. This requires institutions of higher learning, which provide the society with higher talent transfer and reserve, not only to have firstclass discipline, theoretical research and development, as well as technical practice ability, but also to implement good, rational, and timely management of talents while training, gathering talents, and attracting knowledge. This kind of strategic and core management and service mode would put forward higher and more compound requirements for practitioners. In order to handle and balance the coordinated development of multiple fields, such as employment, teaching, scientific research, practice, research, academic exchange, and academic organization, managers need multiple thinking, multiple "brains," and multiple suggestions to support them. The existing teaching management platform needs to provide teaching resources, training, and organization. It also needs to put forward reasonable suggestions for the tasks, development process, and resolutions it undertakes, participate in decision-making, actively improve the administrative and service process, as well as enrich itself with the opportunities close to university talents, teachers, and students.

The teaching management platform covers a large number of teachings, scientific research, management, and visiting resources, facilitating the basic construction of the functions of think tanks. In addition to the tasks of cultivation, teaching management, and coordination undertaken by the management platform in the new era, the platform's functions tend to provide rational decision-making and advice, which would consume more teaching, education, management, and human resources than in the past ${ }^{[2]}$. Combining the comprehensive application of current network, information technology, and high-tech technology, the resource application of teaching management platform is similar to data network, teaching management channels, joint training courses, etc. Although they have not formed a joint development consortium, the existing teaching, scientific research, management, and other resources in the teaching management platform can provide the necessary resources for rational decision-making, teaching, and management suggestions. While administrators gradually extend their administrative power to academic rights and start the interaction of teaching, rights, and knowledge, the teaching management platform would gradually move closer to the functions and attributes of think tanks. The administrative and management members of the teaching management platform also play the part of providing rational resolutions and suggestions; they are also the main force participating in the teaching management reform and the transformation of training programs. However, for the operation of the management platform, only sufficient and comprehensive resources are available to limit the attributes of the management platform to a "resource repository." In order to strengthen the development process of decision-making and suggestions, the teaching management platform needs to fully formulate a joint management system for the development of disciplines, scientific research, and theories in the fields of teaching, scientific research, and management, strengthen the system and content, as well as avoid sectarianism, such as over-administration and overconcentration of rights. Only in this way can it be more conducive to the functional construction of think tanks as well as the progress and expansion of talents and innovative ideas.

\section{Construction and improvement of the think tank function of the teaching management platform}

In order to adapt to the demand for cultivating new talents and the social development trend in the new era, the educational administration as well as the teaching management platforms and institutions in colleges and universities would gradually develop some functional attributes similar to think tanks. Their management structure, power levels, management fields and scope, as well as the functions of relevant think tanks would undergo an overall transformation with the supplement of talents and the expansion of management capabilities. Their management systems, rules, and corresponding rights need to be redefined. The interests, rights, and academic capabilities of various teaching and research groups would be kept in a relatively stable and mutually recognized situation. This means that before initiating academic research, 
organizational cooperation, overall transformation, and functional expansion, the manager of the teaching platform has already taken the role of a decider on various affairs, matters, and administrative rights.

The teaching management organization shall allocate and reserve compound talents proficient in management, academic, and administration as well as further expand its think tank and decision-making functions. Educational and teaching management institutions should enhance their ability to link up decision-making, administration, management, and affairs in the continuous exchange, promotion, and flow of management talents in colleges and universities. At the same time, they should strengthen the organizational structure of teaching management institutions to ensure normal operation. For teaching managers, they should not only be fully aware of the administration and management of affairs, but also have sufficient knowledge, theory, and study measures for discerning affairs, scrutinizing academic contents, and taking into consideration of policy documents. On the platform, the management and decision-making capabilities are displayed according to teaching, scientific research management, and theoretical research activities, forming the "crowd effect" of talents and think tanks, which would objectively provide more independent choices for the teaching management platform and educational administration organizations. Every talent and manager should distinguish different identities in different management scope and affairs; each of them should be responsible for different dimensions of affairs, disciplines, scientific research, and personnel training, emphasizing the distinction and integration of fields and dialectical unity.

A new professional academic, research, and management committee would be set up on the teaching platform to strengthen rational decision-making and multi-center management as well as avoid the risk of extreme decision-making and management style. Teaching management, scientific research platform, and service construction involve many scientific research and teacher-student groups. The rights, interests, and resources that need to be balanced come from multi-dimensional and multi-angle sources. This requires the decision-making departments, institutions, etc. to implement strict discussions, consider all academic, scientific research, and rights factors, and then make decisions. They also need to timely harvest management opinions, follow suggestions, and avoid decision-making risks. Within the educational administration departments, teaching institutions, and management platforms, professional academic, research, and management committees are formed through the chief executives, managers, and combination of disciplines and professional experts. The initial resolution will pass through the committee, taking into consideration the opinions of teachers and student representatives, form a think tank, and formulate a longterm system with stability, so as to encourage everyone to be involved in the management. The managers would form a rational resolution, multi-negotiation thinking habit, and action system. While the teaching platform is endowed with a management center with key rights, the research, study, and discussion on the professional and research-oriented contents of the teaching platform have become an indispensable thinking link in the process from decision-making, negotiation, education, and teaching management to teaching, assignment, and implementation of management tasks.

It is necessary to establish a new management platform and teaching management mechanism centered around the teaching management think tank, form a multi-center linkage management situation, and widely accept suggestions as well as experiences on teaching management inside and outside the school. Upon having the function of a think tank, brainstorm, as well as the establishment of consultation and suggestion committees and groups, it is necessary to correspondingly construct an export-oriented management mechanism with experts, professionals, and managers working together with overlapping identities and a comprehensive system. In the process of teaching management, emphasis is placed on guidance. Especially in the process of teaching syllabus formulation, teaching style formulation, operation of education and teaching management system, as well as theoretical study and development in the field of education, the think tank function of the teaching management platform often needs to be repeatedly operated throughout 
the process.

\section{Funding}

This research was supported by the "Political Construction and Local Governance" Research Center of Nanjing University of Science and Technology - The Key Construction Base of Philosophy and Social Sciences in Universities of Jiangsu.

\section{Disclosure statement}

The author declares that there is no conflict of interest.

\section{References}

[1] Cheng Y, 2019, Application of Knowledge Management Thinking in College Art Education Management. Sichuan Drama, (5): 150-152.

[2] He W, Liu J, 2019, Reflections on the Modernization of Governance System and Governance Capability in Higher Vocational Colleges. Hunan Social Sciences, (3):168-172. 